\title{
A systematic literature review on the joint replenishment problem solutions: 2006-2015
}

\author{
Leonardo dos Santos Lourenço Bastos ${ }^{\mathrm{a} *}$, Matheus Lopes Mendes ${ }^{\mathrm{b}}$, Denilson Ricardo de Lucena \\ Nunes $^{\mathrm{c}}$, André Cristiano Silva Melo ${ }^{\mathrm{c}}$, Mariana Pereira Carneiro ${ }^{\mathrm{c}}$ \\ aPontifícia Universidade Católica do Rio de Janeiro, Rio de Janeiro, RJ, Brasil

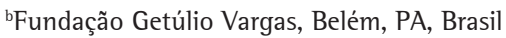 \\ 'Universidade do Estado do Pará, Belém, PA, Brasil \\ *Islbastos@aluno.puc-rio.br
}

\begin{abstract}
Among all existing inventory replenishment models, this research was dedicated to the Joint Replenishment Problem (JRP), which consists in the replenishment of multiple items simultaneously, aiming total cost reduction. Literature has presented several optimal and approximated solutions to this problem, with different applications and techniques, which results in a large quantity of solution proposals. Therefore, this research aimed to map existing solutions to the problem in 2006-2015 in order to provide a guide for interested parts in JRP and to update previous reviews. Hence, systematic review was used to assess papers from that period interval. From a total of 128 papers, a general trend for seeking JRP extensions and practical applications was verified. Furthermore, the heuristic and metaheuristic methods were the most used and considered the most suitable due to their simplicity in understanding and application.
\end{abstract}

Keywords

Inventory management. Multi-product. Joint replenishment problem. Systematic review.

How to cite this article: Bastos, L. S. L., Mendes, M. L., Nunes, D. R. L., Melo, A. C. S., \& Carneiro, M. P. (2017). A systematic literature review on the joint replenishment problem solutions: 2006-2015. Production, 27, e20162229. http://dx.doi. org/10.1590/0103-6513.222916

\section{Introduction}

For decades, more studies on inventory replenishment problems have been developed as the demand for products have increased and the cost reduction became an important objective. On a mathematical perspective, a large amount of solutions has been proposed by means of optimization models, with the objective of reducing costs and fulfilling the demand (Saracoglu et al., 2014). One of the main topics is the Joint Replenishment Problem (JRP), which consists in programming the replenishment of different types of items in the same order, generally provided by the same supplier, aiming total inventory costs reduction (Khouja \& Goyal, 2008).

There is an extensive literature regarding the development of efficient and effective solution models for the JRP, that have been proposed to provide more practical models. Companies seek models to make decisions on inventory management that result in efficient JRP solutions, since the replenishment of multi-items is a common context within the operation environment (Salameh et al., 2014). Furthermore, according to Salameh et al. (2014), the JRP guarantee total cost reduction compared to single-item replenishment.

The JRP is considered NP-Hard due to is combinatorial nature. Therefore, recent studies have focused on finding more efficient and faster solution algorithms, also considering the practical context in where the problem is presented, such as metaheuristic methods, instead of only generating exact solutions, as it results in large computational time (Khouja \& Goyal, 2008; Qu et al., 2015). Porras \& Dekker (2008) assert that the joint replenishment strategy results in saving up to $13 \%$ on the total cost compared to Economic Order Quantity models for a single item approach considering a set of twenty products. 
The practical application of JRP models can be difficult as its complexity may easily increase computational time. The available published literature provides a large variety of models and applications, with different methods, that seek lower computational time, optimal solutions, or, in their minority solving practical approaches. Furthermore, there has been a time gap since the last review about JRP models provided in Khouja \& Goyal (2008), and the update of the state of art on JRP may help researchers and professionals on knowing the latest approaches.

Therefore, this study aimed to map the different existing solution methods for the JRP, by means of Systematic Review, considering the knowledge developed between 2006 and 2015. This range was chosen as an extension to the work developed in Khouja \& Goyal (2008), which performed a review of methods within 1989-2005. Hence, a Systematic Review Protocol was created to guide the review and provide references for those who are interested in the JRP.

In addition to this introduction, this paper presents the concepts regarding the JRP, its terminology and characteristics, as well as the main contributions stated in the literature on Section 2. Then, on Section 3, the systematic research guidelines and the research protocol are presented. The results on Section 4 are shown in categories regarding demand behavior, which were discussed in terms of planning horizon, solution methodology, and main results. Finally, Section 5 presents the conclusion, followed by the References section.

\section{The joint replenishment problem in inventory management}

The JRP occurs when one considers the interdependency among different groups of products in a same order provided by a single supplier, in the inventory replenishment process (Khouja \& Goyal, 2008; Wang et al., 2012b; Salameh et al., 2014). The objective is to optimize the total replenishment cost by reducing the inventory ordering and holding costs (Wang et al., 2012c; Salameh et al., 2014; Qu et al., 2015; Wang et al., 2015). Hence, the joint replenishment presents two advantages: it is possible to earn discounts from the supplier when ordering large batches of multiple items; and the (ordering) fixed costs per item can be reduced as well as the transportation costs (Salameh et al., 2014).

JRP models have presented a large diversity of application. As the problem is considered NP-Hard, it is more difficult to find solutions in acceptable computational time, and that are practical for the decision-making process in companies compared to single-item inventory replenishment models (Khouja \& Goyal, 2008; Wang et al., 2012c). In the literature, models consider two main solving strategies for the JRP (Khouja \& Goyal, 2008): Direct Grouping Strategy (DGS) - products are grouped in sets, in which each group the items follow the same cycle time; and Indirect Grouping Strategy (IGS) - each product has its own cycle time, that is a multiple of a basic cycle time (Wang et al., 2015).

Also, two types of ordering costs are considered: the major ordering cost and minor ordering cost. The former is related to the ordering cost of the whole batch and the latter is associated with each item that composes the order to be replenished (Zhang et al., 2013). In the IGS, for instance, the total cost (TC) is defined as the sum of total holding cost and the total ordering cost, which is composed by the sum of total minor $\left(\mathrm{s}_{\mathrm{i}}\right)$ and major $(\mathrm{S})$ ordering costs, as stated in the Equation $1 . \mathrm{K}$ is the vector of $\mathrm{k}_{\mathrm{i}}$, that corresponds to the integer multipliers of the basic cycle time $\mathrm{T}$ for each product $\mathrm{i}$, and $\mathrm{h}_{\mathrm{i}}$ is the holding cost of each product from the total $\mathrm{n}$ products.

$$
\mathrm{TC}(\mathrm{T}, \mathbf{K})=\mathrm{HC}+\mathrm{OC}=\frac{\mathrm{T}}{2} \sum_{\mathrm{i}=1}^{\mathrm{n}} \mathrm{k}_{\mathrm{i}} \mathrm{D}_{\mathrm{i}} \mathrm{h}_{\mathrm{i}}+\frac{\left(\mathrm{S}+\sum_{\mathrm{i}=1}^{\mathrm{n}} \frac{\mathrm{s}_{\mathrm{i}}}{\mathrm{k}_{\mathrm{i}}}\right)}{\mathrm{T}}
$$

By means of experiments in simulation, it was observed that the IGS was more efficient than the DGS when the ratio major/minor ordering costs was high, and the DGS presented better results mostly in computational time when the ratio was lower (Olsen, 2005; Porras \& Dekker, 2006; Khouja \& Goyal, 2008).

Some of the main JRP solution methods and contributions presented by Khouja \& Goyal (2008) are seen in Table 1. On deterministic models, the main reference is the RAND algorithm, proposed by Kaspi \& Rosenblatt (1991). It is a heuristic that divides equally a range of cycle time values among lower and upper bounds and then it applies Silver (1976)'s algorithm (Khouja \& Goyal, 2008). At the time, RAND was considered the best algorithm due to its satisfactory results for instances with a large product quantity in terms of solution quality and computational time. Furthermore, it can be easily implemented compared to other algorithms, which made it one of the main methods for comparison and validation of newer models (Khouja \& Goyal, 2008).

On the stochastic demand models, there are two main replenishment policies: The can-order policy (COP), by Balintfy (1964), in which if any item reaches a must-order point, a replenishment order is made, and if the 
Table 1. Main solution models for the JRP until 2006.

\begin{tabular}{lll}
\hline \multicolumn{1}{c}{ Demand } & \multicolumn{1}{c}{ Solution approaches } \\
\hline $\begin{array}{l}\text { Deterministic } \\
\text { (non-time varying) }\end{array}$ & $\begin{array}{l}\text { Enumerative Algorithms and Branch-and-Bound, Global } \\
\text { Optimaztion Algorithms, RAND, Heuristics and Genectic } \\
\text { Algorithms. }\end{array}$ & $\begin{array}{l}\text { Goyal \& Deshmukh (1993); van Eijs (1993); Viswanathan } \\
\text { (1996, 2002); Hariga (1994); Wildeman et al. (1997); } \\
\text { Fung \& Ma (2001); Olsen (2005); Porras \& Dekker (2006) }\end{array}$ \\
\hline \multirow{2}{*}{ Dynamic (time varying) } & $\begin{array}{l}\text { Branch-and-bound, Dantzi-Wolf decomposition, Power- } \\
\text { of-Two technique and Heuristics, Dynamic Programming }\end{array}$ & Silver (1979); Lee \& Yao (2003); Boctor et al. (2004) \\
\hline & $\begin{array}{ll}\text { Can-order policy and Periodic Replenishment Policy } \\
\text { variants; Poisson or Normal distribution on demand; }\end{array}$ & $\begin{array}{l}\text { Silver (1981); Pantumsinchai (1992); Johansen \& } \\
\text { Stochastic }\end{array}$ \\
& Policy Parameters estimation; Markov Decision Process. & (2005); Minner \& Silver (2005); Özkaya et al. (2006) \\
\hline Source: Khouja \& Goyal (2008). & &
\end{tabular}

other items present inventory levels below a can-order point, they are included in the same order (Johansen \& Melchiors, 2003; Balintfy, 1964; Khouja \& Goyal, 2008). The periodic replenishment policy (PRP), by Atkins \& lyogun (1988), or (T, M) policy, considers a Poisson distributed demand, in which all products follow the same replenishment periodic interval $\mathrm{T}$, and each one is replaced to a pre-determined inventory level $\mathrm{M}$. Later, it has been considered that a set of products would follow the periodic review interval T, while other products that also should be replenished would follow a section of T (Atkins \& lyogun, 1988; Khouja \& Goyal, 2008).

More sophisticated methods were also used to solve the JRP, such as meta-heuristics, Evolutionary Computing, Genetic Algorithms, and Differential Evolution Algorithm (Wang et al., 2015). Moreover, Khouja \& Goyal (2008) stated that the focus on finding the optimal solution has been saturated and suggested efforts to be directed on the development of more practical models which can be implemented easily in companies. Further details are shown in Khouja \& Goyal (2008).

\subsection{Systematic review}

It comprehends a rigorous process that allows transparency on the steps followed by the research, by means of protocols, to identify, assess and summarize the main contributions on literature regarding a defined topic, diminishing bias and highlighting the review steps of the researcher (Tranfield et al., 2003; Thomé et al., 2016). Therefore, based on previous guidelines, Thomé et al. (2016) presented the following general steps, which may lead researchers while performing a systematic review: Problem Formulation and Review Planning, Literature Search, Data Collection, Data Analysis, Data Synthesis and Interpretation, Results Presentation and Review Update.

\section{Research methodology}

For achieving the objective of mapping the different existing solutions on JRP, this research performed a Systematic Review considering published material in the range 2006-2015. Hence, this study followed the guidelines provided in Tranfield et al. (2003) and Thomé et al. (2016), being the first step the creation of the research question and the Review Protocol.

For this purpose, the question that guided the procedure of the systematic review was defined: "What is the context of JRP inventory studies, published in the period of 2006 to 2015, with respect to the method, context and main results of the solutions?".

After an initial literature review on JRP, the key-words to search papers were obtained. The inclusion criteria comprised of accepting articles that proposed new, revised or improved models on JRP. As exclusion criteria, papers with only single-item replenishment approaches were not considered as they are not JRP.

Therefore, the collection of articles followed the Review Protocol, as shown in Table 2, and they were chosen by analyzing their titles, abstract and keywords, as well as in completely accordance among the authors for acceptance. The use of five electronic databases allowed a fast and broader search for the desired material.

From selected papers, information regarding assumptions of the model and its application was extracted, such as: the solution development method or modelling, the context in which the JRP was presented and the method was applied, as well as the main results obtained, in terms of solution quality (deviation from the best known solutions) and computational time.

The models were categorized by the type of demand (deterministic or stochastic) and information regarding inventory management theory was also obtained, as in Khouja \& Goyal (2008). In addition, complementary approaches in where the JRP is presented indirectly as within a general problem or related to other problems were also considered. 


\begin{tabular}{|c|c|c|c|}
\hline Key-words & Range & Inclusion criteria & Databases \\
\hline \multirow[t]{2}{*}{ Joint Replenishment Problem } & $2006-2015$ & Journal Papers & Web of Science \\
\hline & & $\begin{array}{l}\text { Proposal of models for the JRP - Development and } \\
\text { application of new models or improvements on } \\
\text { previous methods. }\end{array}$ & PROQUEST \\
\hline Joint Replenishment Model & & $\begin{array}{l}\text { Comparisons on JRP models, JRP and single-item } \\
\text { models, literature reviews. }\end{array}$ & SCOPUS \\
\hline \multirow[t]{2}{*}{ Multiple Inventory Replenishment } & & Exclusion criteria & CAPES Journals \\
\hline & & Approaches only on single-item replenishment & Google Scholar \\
\hline
\end{tabular}

\section{Analysis of results}

A total of 128 papers were obtained, which demonstrates a considerable amount of contributions to the topic. As shown in Figure 1, the JRP has been widely studied and its importance implies in continuous research efforts. In addition, the increase in quantity can be justified by the development of faster computation algorithms contributing to the solving of NP-Hard problems as the JRP.

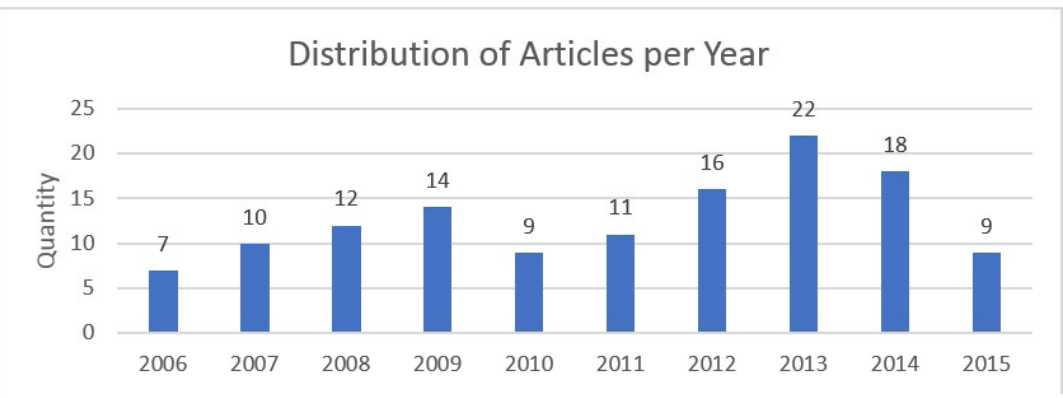

Figure 1. Distribution of Published articles per year from the databases.

As shown in Table 3, the International Journal of Production Economics and the European Journal of Operational Research are those containing most of the selected papers with 18 and 16 articles, respectively. One can verify the JRP is an ongoing topic, which encourages the new studies to extend the application of the multi-item replenishment context, especially due to its advantages in inventory management decisions.

Table 3. Ranking of 10 most frequently publication journals.

\begin{tabular}{lc}
\hline \multicolumn{1}{c}{ Repository } & Articles \\
\hline International Journal of Production Economics & 18 \\
European Journal of Operational Research & 16 \\
Computers \& Operations Research & 7 \\
International Journal of Production Research & 6 \\
Computer Integrated Manufacturing Systems & 6 \\
Operations Research & 6 \\
Expert Systems with Applications & 5 \\
International Journal of Systems Science & 4 \\
The International Journal of Advanced Manufacturing Technology & 4 \\
Transportation Research Part E: Logistics and Transportation Review & 4 \\
\hline
\end{tabular}

In addition, as verified in Table 4, there has been a predominance of models on the Deterministic Demand category (constant and dynamic), even though it had always presented a solid study, followed by the Stochastic Demand models. It can also be noticed a high quantity of articles on complementary approaches of the JRP, which states a broader extension of JRP in the literature 
Table 4. Quantity of Articles per category of demand.

\begin{tabular}{lc}
\hline \multicolumn{1}{c}{ Type of Demand } & Quantity \\
\hline Constant Deterministic & 36 \\
Dynamic Deterministic (time-varying) & 2 \\
Stochastic & 19 \\
Complementary Approaches & 71 \\
\hline
\end{tabular}

The presence of practical applications of the JRP, with a focus on daily problems on companies also confirms that the models aimed obtaining good solutions for cost reduction and not only the optimal cost solution, as suggested by (Khouja \& Goyal, 2008).

\subsection{Deterministic and dynamic demand}

On constant deterministic demand models, it was observed that the infinite horizon planning approach comprehended most papers (80\%), representing a generalization of the JRP application. As shown in Table 5, 24 papers developed heuristic or meta-heuristic methods, which provided easy implementation, using intuitive algorithms on less complex platforms, such as spreadsheets as in Nilsson et al. (2007). Therefore, the JRP has been widely applied to practical problems, and papers showed solutions on lower computational times, compared to exact solutions, what supports Khouja \& Goyal (2008) suggestion for future works.

Table 5. Models on Constant and Dynamic Deterministic Demand.

\begin{tabular}{|c|c|}
\hline Author (Year) & Method \\
\hline $\begin{array}{l}\text { Porras \& Dekker (2006)', Hoque (2006)', Bayindir et al. (2006)', } \\
\text { Zhang et al. (2011)', Zhang (2012)' }\end{array}$ & Global Optimization Algorithms ${ }^{(e)}$ \\
\hline Levi et al. (2006) ${ }^{2}$ & Mixed Integer Programming ${ }^{(\mathrm{e})}$ \\
\hline $\begin{array}{l}\text { Nilsson et al. (2007)', Amaya et al. (2013)', Zhang et al. (2012)', Tsao } \\
\& \text { Teng (2013)', Paul et al. (2014)', Bayley \& Bookbinder (2015)', } \\
\text { Praharsi et al. (2010)', Gutiérrez et al. (2013)' }\end{array}$ & Heuristics $^{(a)}$ \\
\hline Ho (2013)', Salameh et al. (2014)' & Heuristics $^{(e)}$ \\
\hline Moon \& Cha (2006)' & Genetic Algorithm and RAND with Lagrange Multipliers ${ }^{(\mathrm{a})}$ \\
\hline Yoo \& Gen (2007) ${ }^{1}$ & Genetic Algorithm and Simulated Annealing $^{(a)}$ \\
\hline Liang et al. (2009)' & Simulated Annealing and Lagrange Relaxation ${ }^{\text {(a) }}$ \\
\hline Wang \& Cheng (2008) ${ }^{1}$ & RAND $^{(\mathrm{e})}$ \\
\hline Porras \& Dekker (2008)' & Enumerative Algorithm $^{(\mathrm{a})}$ \\
\hline Taleizadeh et al. (2008)' & Harmony Search Algorithm ${ }^{(a)}$ \\
\hline Olsen (2008)', Li et al. (2015)' & Evolutionary Algorithm (a) \\
\hline Hong \& Kim (2009)', Taleizadeh et al. (2013)' & Genetic Algorithm ${ }^{(a)}$ \\
\hline Hsiau \& Lin (2009) ${ }^{1}$ & Simulated Annealing $^{(\text {a) }}$ \\
\hline Taleizadeh et al. (2009) $^{1}$ & Meta-heuristic and Fuzzy Rough Algorithm ${ }^{(\mathrm{a})}$ \\
\hline Taleizadeh et al. (2011)' & $\begin{array}{l}\begin{array}{l}\text { Harmony Search, Rough Simulation and Fuzzy Simulation Algorithms } \\
\text { (Hybrid) }^{\text {(a) }}\end{array} \\
\end{array}$ \\
\hline Wang et al. (2012b) ${ }^{2}$, Wang et al. (2012c) ${ }^{1}$ & $\mathrm{DEA}^{(\mathrm{a})}$ \\
\hline Moon et al. (2011) ${ }^{1}$ & RAND with Heuristics ${ }^{(a)}$ \\
\hline Kang et al $(2013)^{2}$ & Mixed Integer Programming and Particle Swarm Optimization (Hybrid) ${ }^{(\mathrm{e} / \mathrm{a})}$ \\
\hline Durán \& Pozo (2013)' & Particle Swarm Optimization and Genetic Algorithm ${ }^{(\mathrm{a})}$ \\
\hline Yousefi \& Sadjadi (2014) $^{1}$ & RAND and Genetic Algorithm (Hybrid) (a) \\
\hline Wee et al. (2009) $)^{2}$ & Fuzzy Model \& Multi-Objective $^{(a)}$ \\
\hline
\end{tabular}

One of those approaches was the use of cost balancing for approximating a certain solution to the optimal, such as of a ratio between ordering costs and holding costs, and, thus, consisted on a fast decision mean of scheduling orders (Nilsson et al., 2007). Also, the authors justified the use of hybrid algorithms due to the potential complementarity different methods can present for achieving better quality solutions. In addition, one can verify the use of the Differential Evolution Algorithm (DEA), by Wang et al. (2012b, c). While most of the models were based on the IGS, the use of DEA considered the DGS due to a relatively lower computational time for solving the problem. 
Furthermore, there has been a trend in solving practical problems by considering additional situations such as capacity and resource constraints, in Hoque (2006); Porras \& Dekker (2006), Wang \& Cheng (2008), Amaya et al. (2013), Li et al. (2015). Studies of Zhang et al. (2011, 2012) and Zhang (2012) presented the replenishment of a main individual item and its complementary products whose demand is correlated to the former. Other situations considered deterioration factors of products, as in Wee et al. (2009) and Taleizadeh et al. (2013); the incorporation of errors in demand prediction, in Wang \& Cheng (2008); and the presence of a utilization factor for each product as they have been replenished, on Bayindir et al. (2006).

Heuristic models have achieved high quality solutions, which were close to the optimal results they have been compared with in each article. The deviation value from optimal solutions in some models were in average 0.07\% higher in terms of total costs, as in Zhang et al. (2012).

Moreover, there was a small quantity of models performed that comprised the dynamic demand environment, which were Gutiérrez et al. (2013) and Praharsi et al. (2010). Differently from the usual deterministic models, there is not a constant ratio of demand over time, although it is known in advance. Hence, it varies on discrete time intervals, which increases the complexity of problems, especially due to the difficulty in modelling the problem in the analytical form.

Simultaneously, this situation fits the reality of some companies, when replenishment contracts are made. In this case, companies must stablish the correct cycle time for each replenishment to avoid stock-out. Hence, it was verified a large opportunity of researching considering this approach within the deterministic demand models.

\subsection{Stochastic demand}

On stochastic demand models, there was a large quantity of proposals on inventory replenishment policies based on the COP and as it comprises of a continuous review policy, it presented a potential to decrease the quantity of safety inventory in case of a correct estimation of re-order and can-order parameters. The solution methods have focused mostly on determining the optimal values for those parameters and proposed the best suitable values for the can-order policies, as shown in Table 6. Therefore, a total of three papers used a Markov Decision Process approach, as in Minner \& Silver (2007), Kayiş et al. (2008), and Feng et al. (2015). In this case, the demand was considered as a compound Poisson distribution for each type of product to be replenished in the same order. In addition, decomposition methods were also present, in which the JRP was decomposed in several single-item problems one for each type of product, as in Huang \& Chen (2007), Kayiş et al. (2008), and Larsen (2009), and the solution comprehended the merge of each sub-solution obtained.

Table 6. Models on Stochastic Demand.

\begin{tabular}{|c|c|}
\hline Author (Year) & Method \\
\hline Larsen (2009) ${ }^{1}$ & Global Optimization Algorithms ${ }^{(\mathrm{e})}$ \\
\hline $\begin{array}{l}\text { Huang \& Chen (2007)', Eynan \& Kropp (2007)', Moon et al. (2008) } \\
\text { Yao (2010)', Narayanan \& Robinson }(2010)^{2} \text {, Roushdy et al. (2011)', } \\
\text { Karalli \& Flowers (2011)' }\end{array}$ & Heuristics ${ }^{(a)}$ \\
\hline Li et al. (2009)', Nagasawa et al. (2015)' & Genetic Algorithm ${ }^{(a)}$ \\
\hline Minner \& Silver (2007)' & Markov Decision Process and Heuristics ${ }^{(a)}$ \\
\hline Feng et al. (2015)' & Markov Decision Process and Heuristics ${ }^{(a)}$ \\
\hline Kayiş et al. (2008)' & Markov Decision Process, Heuristics and Enumerative Algorithm ${ }^{(a)}$ \\
\hline Tsai et al. (2009)' & Association Clustering Algorithm ${ }^{(a)}$ \\
\hline Kiesmüller (2010)' & Heuristics ${ }^{(a)}$ \\
\hline Hernández et al. (2012)' & Golden-Section Algorithm ${ }^{(a)}$ \\
\hline Wang et al. (2013a)' & Fuzzy Model and Meta-Heuristics (Hybrid) ${ }^{(a)}$ \\
\hline Buchbinder et al. (2013)' & Primal-Dual Algorithm ${ }^{(a)}$ \\
\hline Wang et al. (2015)' & Meta-heuristics $^{(a)}$ \\
\hline
\end{tabular}

Studies regarding stochastic demands have presented a higher complexity to the JRP, due to the uncertainty parameters, although they approximate real situations. However, a few papers good results in terms of cost, as in the analysis of Eynan \& Kropp (2007) and Kayiş et al. (2008), including more efficiency than Pantumsinchai (1992). On comparisons with RAND, some proposed models were lower or approximated in performance, which highlights the importance of the former for solving JRP, even in the stochastic environment (Hernández et al., 2012). 


\subsection{Complementary approaches}

In this category, the first main indirect application of the JRP was presented in the Multi-echelon problems, which considered stage models covering three stages on a supply chain, mostly suppliers, manufacturer and retailer, as it is shown in Table 7. The next applications are also considered as particular situations of the multi-echelon context as they connect two different supply chain stages. The three main approaches comprehend a total of 40 papers.

Table 7. Main problems and related works on complementary approaches for the JRP.

\begin{tabular}{|c|c|}
\hline Context & Related works \\
\hline Multi-echelon & $\begin{array}{l}\text { Özkaya et al. (2006), Pourakbar et al. (2007), Jung \& Mathur (2007), Chen \& Chen (2007), Qinglong et al. (2008), Nonner } \\
\text { \& Souza (2009), Hsu (2009), Tsao (2010), Hajji et al. (2011), Tsao \& Sheen (2012), Zhou et al. (2013), Wang et al. (2013b), } \\
\text { Ben-Daya et al. (2013), Sana et al. (2014), Büyükkaramikli et al. (2013), Coelho \& Laporte (2014), Wang et al. (2014), } \\
\text { Cordeau et al. (2015) }\end{array}$ \\
\hline SWMR & $\begin{array}{l}\text { Anily \& Haviv (2007), Cha et al. (2008), Zhang (2009), Minner (2009), Abdul-Jalbar et al. (2010), Solyalđ et al. (2010), } \\
\text { Fiestras-Janeiro et al. (2011), Elomri et al. (2012), Yang et al. (2012), Dror et al. (2012), Larsen \& Turkensteen (2014), Yi \& } \\
\text { Reklaitis (2014), Praharsi et al. (2014), Ho et al. (2014), Verma et al. (2014), Pukcarnon et al. (2014) }\end{array}$ \\
\hline JRD & $\begin{array}{l}\text { Huang \& Lin (2010), Wang et al. (2012a), Qu et al. (2013), Wang et al. (2013c), Cui et al. (2014), Zeng et al. (2014), } \\
\text { Nagarajan \& Shi (2015) }\end{array}$ \\
\hline
\end{tabular}

In second, there were models on the Single Warehouse Multi-retailer problem (SWMR), in which a warehouse must manage the replenishments from suppliers to a set of retailers, finding the optimal configuration of the system (Yang et al., 2012), as well as the Joint Replenishment \& Delivery Problem (JRD), which approaches the delivery scheduling (routing) of multi-products along with the joint replenishment problem (Pukcarnon et al., 2014).

Other less frequent approaches involved very specific problems, which presented a diversity of models for solving multi-product related problems, especially considering practical application in companies. Therefore, the inclusion of the JRP in other problems is able to state the importance of including the multi-product environment on solving models regarding inventory replenishment, and have the potential of being the basis for the development of new specific and practical studies.

\section{Conclusion}

This study performed a literature review on the existing solutions for the JRP published between 2006 and 2015 , and resulted in an information base about the main models, updating the review of Khouja \& Goyal (2008), with a total of 139 selected papers. Most of them still have presented applications to constant and dynamic deterministic demands. However, the studies regarding the stochastic demand are also increasing as they approximate to practical situations. The research question was answered and the objective was achieved.

For all demand categories, authors could highlight which meta-heuristics were most used. One of the reasons was their simplicity in implementation and understanding, and presented lower computational time compared to exact algorithms, with good quality solutions. Also, for situations in where the planning horizon is large (years), a high computational time could be accepted, since the model would be used less frequently.

Furthermore, indirect approaches on the JRP were also verified, in which it was used in other problems from more general situations. In this case, there has been an extension of the problem, that considered applications for multi-echelon (three-stage replenishment), as well as related to the Single-Warehouse and Multi-Retailer problems. Hence, there has been a trend on models for simplifying the application and implementation of solution methods resulting in lower computational time as well.

Therefore, for future works, it is suggested for this review to be updated periodically to offer an up-to-date repository of models that can be used for academic or professionals interested in the JRP. Furthermore, the new development of models on dynamic demand and stochastic demand due to the opportunity of research on the form and the high complexity of the latter, which can present challenges for developing more efficient methods, and, hence, encourage the studying on the JRP.

\section{References}

Abdul-Jalbar, B., Segerstedt, A., Sicilia, J., \& Nilsson, A. (2010). A new heuristic to solve the one-warehouse N-retailer problem. Computers \& Operations Research, 37(2), 265-272. http://dx.doi.org/10.1016/j.cor.2009.04.012. 
Amaya, C. A., Carvajal, J., \& Castaño, F. (2013). A heuristic framework based on linear programming to solve the constrained joint replenishment problem (C-JRP). International Journal of Production Economics, 144(1), 243-247. http://dx.doi.org/10.1016/j. ijpe.2013.02.008.

Anily, S., \& Haviv, M. (2007). The cost allocation problem for the first order interaction joint replenishment model. Operations Research, 55(2), 292-302. http://dx.doi.org/10.1287/opre.1060.0346.

Atkins, D. R., \& lyogun, P. O. (1988). Periodic versus "can-order" policies for coordinated multi-item inventory systems. Management Science, 34(6), 791-796. http://dx.doi.org/10.1287/mnsc.34.6.791.

Balintfy, J. L. (1964). On a basic class of multi-item inventory problems. Management Science, 10(2), 287-297. http://dx.doi.org/10.1287/ mnsc.10.2.287.

Bayindir, Z. P., Birbil, Ş. İ., \& Frenk, J. B. G. (2006). The joint replenishment problem with variable production costs. European Journal of Operational Research, 175(1), 622-640. http://dx.doi.org/10.1016/j.ejor.2005.06.005.

Bayley, T. A., \& Bookbinder, J. H. (2015). The dynamic family assignment heuristic. IFAC-PapersOnLine, 48(3), 1161-1166. http://dx.doi. org/10.1016/j.ifacol.2015.06.241.

Ben-Daya, M., As'ad, R., \& Seliaman, M. (2013). An integrated production inventory model with raw material replenishment considerations in a three-layer supply chain. International Journal of Production Economics, 143(1), 53-61. http://dx.doi.org/10.1016/j.jpe.2010.10.024.

Boctor, F. F., Laporte, G., \& Renaud, J. (2004). Models and algorithms for the dynamic-demand joint replenishment problem. International Journal of Production Research, 42(13), 2667-2678. http://dx.doi.org/10.1080/00207540410001671660.

Buchbinder, N., Kimbrel, T., Levi, R., Makarychev, K., \& Sviridenko, M. (2013). Online make-to-order joint replenishment model: primaldual competitive algorithms. Operations Research, 61(4), 1014-1029. http://dx.doi.org/10.1287/opre.2013.1188.

Büyükkaramikli, N. C., Gürler, Ü., \& Alp, 0. (2013). Coordinated logistics: joint replenishment with capacitated transportation for a supply chain. Production and Operations Management, 23(1), 110-126. http://dx.doi.org/10.1111/poms.12041.

Cha, B. C., Moon, l. K., \& Park, J. H. (2008). The joint replenishment and delivery scheduling of the one-warehouse, n-retailer system. Transportation Research Part E, Logistics and Transportation Review, 44(5), 720-730. http://dx.doi.org/10.1016/j.tre.2007.05.010.

Chen, J.-M., \& Chen, T.-H. (2007). The profit-maximization model for a multi-item distribution channel. Transportation Research Part E, Logistics and Transportation Review, 43(4), 338-354. http://dx.doi.org/10.1016/j.tre.2005.12.001.

Coelho, L. C., \& Laporte, G. (2014). Optimal joint replenishment, delivery and inventory management policies for perishable products. Computers \& Operations Research, 47, 42-52. http://dx.doi.org/10.1016/j.cor.2014.01.013.

Cordeau, J.-F., Laganà, D., Musmanno, R., \& Vocaturo, F. (2015). A decomposition-based heuristic for the multiple-product inventoryrouting problem. Computers \& Operations Research, 55, 153-166. http://dx.doi.org/10.1016/j.cor.2014.06.007.

Cui, L., Wang, L., \& Deng, J. (2014). RFID technology investment evaluation model for the stochastic joint replenishment and delivery problem. Expert Systems with Applications, 41(4), 1792-1805. http://dx.doi.org/10.1016/j.eswa.2013.08.078.

Dror, M., Hartman, B. C., \& Chang, W. (2012). The cost allocation issue in joint replenishment. International Journal of Production Economics, 135(1), 242-254. http://dx.doi.org/10.1016/j.jpe.2011.07.015.

Durán, 0., \& Pozo, L. P. (2013). Solution of the spare parts joint replenishment problem with quantity discounts using a discrete particle swarm optimization technique. Studies in Informatics and Control, 22(4), 319-328.

Elomri, A., Ghaffari, A., Jemai, Z., \& Dallery, Y. (2012). Coalition formation and cost allocation for joint replenishment systems. Production and Operations Management, 21(6), 1015-1027. http://dx.doi.org/10.1111/j.1937-5956.2012.01333.x.

Eynan, A., \& Kropp, D. H. (2007). Effective and simple EOQ-like solutions for stochastic demand periodic review systems. European Journal of Operational Research, 180(3), 1135-1143. http://dx.doi.org/10.1016/j.ejor.2006.05.015.

Feng, H., Wu, Q., Muthuraman, K., \& Deshpande, V. (2015). Replenishment policies for multi-product stochastic inventory systems with correlated demand and joint-replenishment costs. Production and Operations Management, 24(4), 647-664. http://dx.doi. org/10.1111/poms. 12290 .

Fiestras-Janeiro, M. G., García-Jurado, 1., Meca, A., \& Mosquera, M. A. (2011). Cooperative game theory and inventory management. European Journal of Operational Research, 210(3), 459-466. http://dx.doi.org/10.1016/j.ejor.2010.06.025.

Fung, R. Y. K., \& Ma, X. (2001). A new method for joint replenishment problems. The Journal of the Operational Research Society, 52(3), 358-362. http://dx.doi.org/10.1057/palgrave.jors.2601091.

Goyal, S. K., \& Deshmukh, S. G. (1993). Discussion A note on ‘The economic ordering quantity for jointly replenishing items'. International Journal of Production Research, 31(12), 2959-2961. http://dx.doi.org/10.1080/00207549308956910.

Gutiérrez, J., Colebrook, M., Abdul-Jalbar, B., \& Sicilia, J. (2013). Effective replenishment policies for the multi-item dynamic lot-sizing problem with storage capacities. Computers \& Operations Research, 4O(12), 2844-2851. http://dx.doi.org/10.1016/j.cor.2013.06.007.

Hajji, A., Gharbi, A., Kenne, J.-P., \& Pellerin, R. (2011). Production control and replenishment strategy with multiple suppliers. European Journal of Operational Research, 208(1), 67-74. http://dx.doi.org/10.1016/j.ejor.2010.08.010.

Hariga, M. (1994). Two new heuristic procedures for the joint replenishment problem. The Journal of the Operational Research Society, 45(4), 463-471. http://dx.doi.org/10.1057/jors.1994.64.

Hernández, S., Flores, 1., \& Vázquez, J. A. (2012). Improved golden-section algorithm for the multi-item replenishment problem. Journal of Applied Research and Technology, 10(3), 388-397.

Ho, W.-T. (2013). Determining the optimum ordering policy in multi-item joint replenishment problem using a novel method. Mathematical Problems in Engineering, 2013, 1-9. http://dx.doi.org/10.1155/2013/469794.

Ho, W.-T., Lai, S.-F., \& Huang, Y.-K. (2014). An optimal mixed batch shipment policy for multiple items in a single-supplier multiple-retailer integrated system. Journal of Optimization Theory and Applications, 160(2), 636-658. http://dx.doi.org/10.1007/s10957-013-0280-1.

Hong, S. P., \& Kim, Y.-H. (2009). A genetic algorithm for joint replenishment based on the exact inventory cost. Computers \& Operations Research, 36(1), 167-175. http://dx.doi.org/10.1016/j.cor.2007.08.006.

Hoque, M. A. (2006). An optimal solution technique for the joint replenishment problem with storage and transport capacities and budget constraints. European Journal of Operational Research, 175(2), 1033-1042. http://dx.doi.org/10.1016/j.ejor.2005.06.022. 
Hsiau, H.-J., \& Lin, C.-W. R. (2009). An optimal supply policy for multi-product multi-retailer using simulated annealing method. International Journal of Business and Management, 4(12), 91-98. http://dx.doi.org/10.5539/ijbm.v4n12p91.

Hsu, S.-L. (2009). Optimal joint replenishment decisions for a central factory with multiple satellite factories. Expert Systems with Applications, 36(2), 2494-2502. http://dx.doi.org/10.1016/j.eswa.2008.01.069.

Huang, S., \& Chen, J. (2007). Analytical study of multi-item joint replenishment problem. Systems Engineering Theory \& Practice, 27(12), 90-95. http://dx.doi.org/10.1016/S1874-8651(08)60076-9.

Huang, S.-H., \& Lin, P.-C. (2010). A modified ant colony optimization algorithm for multi-item inventory routing problems with demand uncertainty. Transportation Research Part e: Logistics and Transportation Review, 46(5), 598-611. http://dx.doi.org/10.1016/j. tre.2010.01.006.

Johansen, S. G., \& Melchiors, P. (2003). Can-order policy for the periodic-review joint replenishment problem. The Journal of the Operational Research Society, 54(3), 283-290. http://dx.doi.org/10.1057/palgrave.jors.2601499.

Jung, J., \& Mathur, K. (2007). An efficient heuristic algorithm for a two-echelon joint inventory and routing problem. Transportation Science, 41(1), 55-73. http://dx.doi.org/10.1287/trsc.1060.0160.

Kang, H.-Y., Lee, A. H. 1., \& Lee, C.-H. (2013). A joint replenishment model under transportation batch and quantity discounts. New York: Global Business and Technology Association.

Karalli, S. M., \& Flowers, A. D. (2011). The JRP with multiple replenishment sources and fill rates. California Journal of Operations Management, 9(2), 1-19.

Kaspi, M., \& Rosenblatt, M. J. (1991). On the economic ordering quantity for jointly replenished items. International Journal of Production Research, 29(1), 107-114. http://dx.doi.org/10.1080/00207549108930051.

Kayiş, E., Bilgiç, T., \& Karabulut, D. (2008). A note on the can-order policy for the two-item stochastic joint-replenishment problem. IIE Transactions, 4O(1), 84-92. http://dx.doi.org/10.1080/07408170701246740.

Khouja, M., \& Goyal, S. K. (2008). A review of the joint replenishment problem literature: 1989-2005. European Journal of Operational Research, 186(1), 1-16. http://dx.doi.org/10.1016/j.ejor.2007.03.007.

Kiesmüller, G. P. (2010). Multi-item inventory control with full truckloads: a comparison of aggregate and individual order triggering. European Journal of Operational Research, 200(1), 54-62. http://dx.doi.org/10.1016/j.ejor.2008.12.008.

Larsen, C. (2009). The Q(s,S) control policy for the joint replenishment problem extended to the case of correlation among item-demands. International Journal of Production Economics, 118(1), 292-297. http://dx.doi.org/10.1016/j.jpe.2008.08.025.

Larsen, C., \& Turkensteen, M. (2014). A vendor managed inventory Model using continuous approximations for route length estimates and Markov chain modeling for cost estimates. International Journal of Production Economics, 157, 120-132. http://dx.doi. org/10.1016/j.ijpe.2014.08.001.

Lee, F. C., \& Yao, M. J. (2003). A global optimum search algorithm for the joint replenishment problem under power-of-two policy. Computers \& Operations Research, 30(9), 1319-1333. http://dx.doi.org/10.1016/S0305-0548(02)00073-4.

Lee, L. H., \& Chew, E. P. (2005). A dynamic joint replenishment policy with auto-correlated demand. European Journal of Operational Research, 165(3), 729-747. http://dx.doi.org/10.1016/j.ejor.2003.04.010.

Levi, R., Roundy, R. O., \& Shmoys, D. B. (2006). Primal-dual algorithms for deterministic inventory problems. Mathematics of Operations Research, 31(2), 267-284. http://dx.doi.org/10.1287/moor.1050.0178.

Li, C., Gao, J., Zhang, T., \& Wang, X. (2015). Differential evolution algorithm for constraint joint replenishment problem with indirect grouping strategy. International Journal of Hybrid Information Technology, 8(5), 259-266. http://dx.doi.org/10.14257/ijhit.2015.8.5.28.

Li, C., Xu, X., \& Zhan, D. (2009). Solving joint replenishment problem with deteriorating items using genetic algorithm. Journal of Advanced Manufacturing Systems, 8(1), 47-56. http://dx.doi.org/10.1142/S0219686709001626.

Liang, Z., Zhao, F., \& Cao, M. (2009). Algorithm of deterministic joint replenishment problem (pp. 2835-2843). Reston: ASCE. http:// dx.doi.org/10.1061/40996(330)419.

Minner, S. (2009). A comparison of simple heuristics for multi-product dynamic demand lot sizing with limited warehouse capacity. International Journal of Production Economics, 118(1), 305-310. http://dx.doi.org/10.1016/j.jpe.2008.08.034.

Minner, S., \& Silver, E. A. (2005). Multi-product batch replenishment strategies under stochastic demand and a joint capacity constraint. IIE Transactions, 37(5), 469-479. http://dx.doi.org/10.1080/07408170590918254.

Minner, S., \& Silver, E. A. (2007). Replenishment policies for multiple products with Compound-Poisson demand that share a common warehouse. International Journal of Production Economics, 108(1-2), 388-398. http://dx.doi.org/10.1016/j.jpe.2006.12.028.

Moon, 1. K., \& Cha, B. C. (2006). The joint replenishment problem with resource restriction. European Journal of Operational Research, 173(1), 190-198. http://dx.doi.org/10.1016/j.ejor.2004.11.020.

Moon, 1. K., Cha, B. C., \& Kim, S. K. (2008). Offsetting inventory cycles using mixed integer programming and genetic algorithm. International Journal of Industrial Engineering: Theory, Applications and Practice, 15(3), 245-256.

Moon, I. K., Cha, B. C., \& Lee, C. U. (2011). The joint replenishment and freight consolidation of a warehouse in a supply chain. International Journal of Production Economics, 133(1), 344-350. http://dx.doi.org/10.1016/j.jpe.2009.10.030.

Nagarajan, V., \& Shi, C. (2015). Approximation algorithms for inventory problems with submodular or routing Costs. Computer Research Repository, 160(1), 225-244. http://dx.doi.org/10.1007/s10107-016-0981-y.

Nagasawa, K., Irohara, T., Matoba, Y., \& Liu, S. (2015). Applying Genetic Algorithm for Can-Order Policies in the Joint Replenishment Problem. Industrial Engineering and Management Systems, 14(1), 1-10. http://dx.doi.org/10.7232/iems.2015.14.1.001.

Narayanan, A., \& Robinson, P. (2010). Efficient and effective heuristics for the coordinated capacitated lot-size problem. European Journal of Operational Research, 203(3), 583-592. http://dx.doi.org/10.1016/j.ejor.2009.08.015.

Nielsen, C., \& Larsen, C. (2005). An analytical study of the Q (s, S) policy applied to the joint replenishment problem. European Journal of Operational Research, 163(3), 721-732. http://dx.doi.org/10.1016/j.ejor.2004.02.003.

Nilsson, A., Segerstedt, A., \& Sluis, E. V. D. S. (2007). A new iterative heuristic to solve the joint replenishment problem using a spreadsheet technique. International Journal of Production Economics, 108(1-2), 399-405. http://dx.doi.org/10.1016/j.ijpe.2006.12.022. 
Nonner, T., \& Souza, A. (2009). Approximating the joint replenishment problem with deadlines. Discrete Mathematics, Algorithms, and Applications, 1(2), 153-173. http://dx.doi.org/10.1142/S1793830909000130.

Olsen, A. L. (2005). An evolutionary algorithm to solve the joint replenishment problem using direct grouping. Computers \& Industrial Engineering, 48(2), 223-235. http://dx.doi.org/10.1016/j.cie.2005.01.010.

Olsen, A. L. (2008). Inventory replenishment with interdependent ordering costs: an evolutionary algorithm solution. International Journal of Production Economics, 113(1), 359-369. http://dx.doi.org/10.1016/j.jpe.2007.09.004.

Özkaya, B. Y., Gürler, Ü., \& Berk, E. (2006). The stochastic joint replenishment problem: a new policy, analysis, and insights. Naval Research Logistics, 53(6), 525-546. http://dx.doi.org/10.1002/nav.20147.

Pantumsinchai, P. (1992). A comparison of three joint ordering inventory policies. Decision Sciences, 23(1), 111-127. http://dx.doi. org/10.1111/j.1540-5915.1992.tb00379.x.

Paul, S., Wahab, M. 1. M., \& Ongkunaruk, P. (2014). Joint replenishment with imperfect items and price discount. Computers \& Industrial Engineering, 74, 179-185. http://dx.doi.org/10.1016/j.cie.2014.05.015.

Porras, E., \& Dekker, R. (2006). An efficient optimal solution method for the joint replenishment problem with minimum order quantities. European Journal of Operational Research, 174(3), 1595-1615. http://dx.doi.org/10.1016/j.ejor.2005.02.056.

Porras, E., \& Dekker, R. (2008). A solution method for the joint replenishment problem with correction factor. International Journal of Production Economics, 113(2), 834-851. http://dx.doi.org/10.1016/j.jpe.2007.11.008.

Pourakbar, M., Farahani, R. Z., \& Asgari, N. (2007). A joint economic lot-size model for an integrated supply network using genetic algorithm. Applied Mathematics and Computation, 189(1), 583-596. http://dx.doi.org/10.1016/j.amc.2006.11.116.

Praharsi, Y., Nataliani, Y., \& Wee, H.-M. (2014). An innovative heuristic in multi-item replenishment problem for one warehouse and $\mathrm{N}$ retailers. Journal Teknik Industri, 16(1), 1-8. http://dx.doi.org/10.9744/jti.16.1.1-8.

Praharsi, Y., Purnomo, H. G., \& Wee, H.-M. (2010). An innovative heuristic for joint replenishment problem with deterministic and stochastic demand. International Journal of Electronic Business Management, 8(3), 223-230.

Pukcarnon, V., Chaovalitwongse, P., \& Phumchusri, N. (2014). The can-order policy for one-warehouse N-retailer inventory system: a heuristic approach. English Journal, 18(4), 53-72. http://dx.doi.org/10.4186/ej.2014.18.4.53.

Qinglong, G., Liang, L., Xu, C., \& Zha, Y. (2008). A modified joint inventory policy for VMl systems. International Journal of Information Technology \& Decision Making, 2(7), 225-240. http://dx.doi.org/10.1142/S0219622008002892.

Qu, H., Wang, L., \& Liu, R. (2015). A contrastive study of the stochastic location-inventory problem with joint replenishment and independent replenishment. Expert Systems with Applications, 42(4), 2061-2072. http://dx.doi.org/10.1016/j.eswa.2014.10.017.

Qu, H., Wang, L., \& Zeng, Y.-R. (2013). Modeling and optimization for the joint replenishment and delivery problem with heterogeneous items. Knowledge-Based Systems, 54, 207-215. http://dx.doi.org/10.1016/j.knosys.2013.09.013.

Roushdy, B., Sobhy, N., Abdelhamid, A., \& Mahmoud, A. (2011). Inventory control for a joint replenishment problem with stochastic demand. world Academy of Science, Engineering and Technology, 5(1), 775-779.

Salameh, M. K., Yassine, A. A., Maddah, B., \& Ghaddar, L. (2014). Joint replenishment model with substitution. Applied Mathematical Modelling, 38(14), 3662-3671. http://dx.doi.org/10.1016/j.apm.2013.12.008.

Sana, S. S., Chedid, J. A., \& Navarro, K. S. (2014). A three-layer supply chain model with multiple suppliers, manufacturers and retailers for multiple items. Applied Mathematics and Computation, 229, 139-150. http://dx.doi.org/10.1016/j.amc.2013.12.006.

Saracoglu, l., Topaloglu, S., \& Keskinturk, T. (2014). A genetic algorithm approach for multi-product multi-period continuous review inventory models. Expert Systems with Applications, 41(18), 8189-8202. http://dx.doi.org/10.1016/j.eswa.2014.07.003.

Silver, E. A. (1976). A simple method of determining order quantities in joint replenishments under deterministic demand. Management Science, 22(12), 1351-1361. http://dx.doi.org/10.1287/mnsc.22.12.1351.

Silver, E. A. (1979). Coordinated replenishments of items under time-varying demand: dynamic programming formulation. Naval Research Logistics Quarterly, 26(1), 141-151. http://dx.doi.org/10.1002/nav.3800260113.

Silver, E. A. (1981). Establishing reorder points in the (S, c, s) coordinated control system under compound Poisson demand. International Journal of Production Research, 19(6), 743-750. http://dx.doi.org/10.1080/00207548108956705.

Solyalđ, 0., Süral, H., \& Denizel, M. (2010). The one-warehouse multi-retailer problem with an order-up-to level inventory policy. Naval Research Logistics, 577), 653-666. http://dx.doi.org/10.1002/nav.20428.

Taleizadeh, A. A., Moghadasi, H., Niaki, S. T. A., \& Eftekhari, A. (2008). An economic order quantity under joint replenishment policy to supply expensive imported raw materials with payment in advance. Journal of Applied Sciences, 23(8), 4263-4273. http://dx.doi. org/10.3923/jas.2008.4263.4273.

Taleizadeh, A. A., Niaki, S. T. A., \& Nikousokhan, R. (2011). Constraint multiproduct joint-replenishment inventory control problem using uncertain programming. Applied Soft Computing, 11(8), 5143-5154. http://dx.doi.org/10.1016/j.asoc.2011.05.045.

Taleizadeh, A. A., Nikpour, S., \& Zarei, M. (2009). Constraint joint-replenishment inventory control problem with fuzzy rough demand. Journal of Applied Sciences, 9(4), 627-638. http://dx.doi.org/10.3923/jas.2009.627.638.

Taleizadeh, A. A., Wee, H.-M., \& Jolai, F. (2013). Revisiting a Fuzzy rough economic order quantity model for deteriorating items considering quantity discount and prepayment. Mathematical and Computer Modelling, 57(5-6), 1466-1479. http://dx.doi. org/10.1016/j.mcm.2012.12.008.

Thomé, A. M. T., Scavarda, L. F., \& Scavarda, A. J. (2016). Conducting systematic literature review in operations management. Production Planning and Control, 27(5), 408-420. http://dx.doi.org/10.1080/09537287.2015.1129464.

Tranfield, D., Denyer, D., \& Smart, P. (2003). Towards a methodology for developing evidence-informed management knowledge by means of systematic review. British Journal of Management, 14(3), 207-222. http://dx.doi.org/10.1111/1467-8551.00375.

Tsai, C.-Y., Tsai, C.-Y., \& Huang, P.-W. (2009). An association clustering algorithm for can-order policies in the joint replenishment problem. International Journal of Production Economics, 117(1), 30-41. http://dx.doi.org/10.1016/j.jpe.2008.08.056.

Tsao, Y.-C. (2010). Managing multi-echelon multi-item channels with trade allowances under credit period. International Journal of Production Economics, 127(2), 226-237. http://dx.doi.org/10.1016/j.jpe.2009.08.010. 
Tsao, Y.-C., \& Sheen, G.-J. (2012). A multi-item supply chain with credit periods and weight freight cost discounts. International Journal of Production Economics, 135(1), 106-115. http://dx.doi.org/10.1016/j.jpe.2010.11.013.

Tsao, Y.-C., \& Teng, W.-G. (2013). Heuristics for the joint multi-item replenishment problem under trade credits. IMA Journal of Management Mathematics, 24(1), 63-77. http://dx.doi.org/10.1093/imaman/dps004.

van Eijs, M. J. G. (1993). A note on the joint replenishment problem under constant demand. The Journal of the Operational Research Society, 44(2), 185-191. http://dx.doi.org/10.1057/jors.1993.31.

Verma, N. K., Chakraborty, A., \& Chatterjee, A. K. (2014). Joint replenishment of multi retailer with variable replenishment cycle under VMl. European Journal of Operational Research, 233(3), 787-789. http://dx.doi.org/10.1016/j.ejor.2013.10.001.

Viswanathan, S. (1996). A new optimal algorithm for the joint replenishment problem. The Journal of the Operational Research Society, 477), 936-944. http://dx.doi.org/10.1057/jors.1996.119.

Viswanathan, S. (2002). On optimal algorithms for the joint replenishment problem. The Journal of the Operational Research Society, 53(11), 1286-1290. http://dx.doi.org/10.1057/palgrave.jors.2601445.

Wang, L., Dun, C.-X., Bi, W.-J., \& Zeng, Y.-R. (2012a). An effective and efficient differential evolution algorithm for the integrated stochastic joint replenishment and delivery model. Knowledge-Based Systems, 36, 104-114. http://dx.doi.org/10.1016/j.knosys.2012.06.007.

Wang, L., He, J., \& Zeng, Y.-R. (2012b). A differential evolution algorithm for joint replenishment problem using direct grouping and its application. Expert Systems: International Journal of Knowledge Engineering and Neural Networks, 29(5), 429-441. http://dx.doi. $\operatorname{org} / 10.1111 / \mathrm{j} .1468-0394.2011 .00594 . x$.

Wang, L., He, J., Wu, D., \& Zeng, Y.-R. (2012c). A novel differential evolution algorithm for joint replenishment problem under interdependence and its application. International Journal of Production Economics, 135(1), 190-198. http://dx.doi.org/10.1016/j. ijpe.2011.06.015.

Wang, L., Fu, Q.-L., Lee, C.-G., \& Zeng, Y.-R. (2013a). Model and algorithm of Fuzzy joint replenishment problem under credibility measure on Fuzzy goal. Knowledge-Based Systems, 39, 57-66. http://dx.doi.org/10.1016/j.knosys.2012.10.002.

Wang, L., Qu, H., Chen, T., \& Yan, F.-P. (2013b). An effective hybrid self-adapting differential evolution algorithm for the joint replenishment and location-inventory problem in a three-level supply chain. TheScientificWorldJournal, 2013, 1-11. PMid:24453822.

Wang, L., Qu, H., Li, Y., \& He, J. (2013c). Modeling and optimization of stochastic joint replenishment and delivery scheduling problem with uncertain costs. Discrete Dynamics in Nature and Society, 2013, 1-12. http://dx.doi.org/10.1155/2013/657465.

Wang, L., Qu, H., Liu, S., \& Chen, C. (2014). Optimizing the joint replenishment and channel coordination problem under supply chain environment using a simple and effective differential evolution algorithm. Discrete Dynamics in Nature and Society, 2014, 1-12. http://dx.doi.org/10.1155/2014/675721.

Wang, L., Shi, Y., \& Liu, S. (2015). An improved fruit fly optimization algorithm and its application to joint replenishment problems. Expert Systems with Applications, 42(9), 4310-4323. http://dx.doi.org/10.1016/j.eswa.2015.01.048.

Wang, Y.-C., \& Cheng, W.-T. (2008). A sensitivity analysis of solving joint replenishment problems using the RAND method under inaccurate holding cost estimates and demand forecasts. Computers \& Industrial Engineering, 55(1), 243-252. http://dx.doi. org/10.1016/j.cie.2007.12.010.

Wee, H.-M., Lo, C.-C., \& Hsu, P.-H. (2009). A multi-objective joint replenishment inventory model of deteriorated items in a Fuzzy environment. European Journal of Operational Research, 197(2), 620-631. http://dx.doi.org/10.1016/j.ejor.2006.08.067.

Wildeman, R. E., Frenk, J. B. G., \& Dekker, R. (1997). An efficient optimal solution method for the joint replenishment problem. European Journal of Operational Research, 99(2), 433-444. http://dx.doi.org/10.1016/S0377-2217(96)00072-0.

Yang, W., Chan, F. T., \& Kumar, V. (2012). Optimizing replenishment polices using genetic algorithm for single-warehouse multi-retailer system. Expert Systems with Applications, 39(3), 3081-3086. http://dx.doi.org/10.1016/j.eswa.2011.08.171.

Yao, M.-J. (2010). A search algorithm for solving the joint replenishment problem in a distribution center with warehouse-space restrictions. International Journal of Operations Research, 7(2), 45-60.

Yi, G., \& Reklaitis, G. V. (2014). Adaptive model predictive inventory controller for multiproduct warehouse system. Automatica, 50(9), 2245-2253. http://dx.doi.org/10.1016/j.automatica.2014.07.022.

Yoo, M., \& Gen, M. (2007). Joint replenishment problem with multisupplier using hybrid genetic algorithm. Journal of Japan Industrial Management Association, 571), 497-502.

Yousefi, 0., \& Sadjadi, S. J. (2014). Solving a new bi-objective joint replenishment inventory model with modified RAND and genetic algorithms. Turkish Journal of Electrical Engineering \& Computer Sciences, 22, 1338-1353. http://dx.doi.org/10.3906/elk-1205-22.

Zeng, Y.-R., Wang, L., Xu, X.-H., \& Fu, Q.-L. (2014). Optimizing the joint replenishment and delivery scheduling problem under fuzzy environment using inverse weight fuzzy nonlinear programming method. Abstract and Applied Analysis, 2014, 1-13. http://dx.doi. org/10.1155/2014/904240.

Zhang, J. (2009). Cost allocation for joint replenishment models. Operations Research, 571), 146-156. http://dx.doi.org/10.1287/ opre.1070.0491.

Zhang, R. (2012). An extension of partial backordering EOQ with correlated demand caused by cross-selling considering multiple minor items. European Journal of Operational Research, 220(3), 876-881. http://dx.doi.org/10.1016/j.ejor.2012.02.015.

Zhang, R., Kaku, 1., \& Xiao, Y. (2011). Deterministic EOQ with partial backordering and correlated demand caused by cross-selling. European Journal of Operational Research, 210(3), 537-551. http://dx.doi.org/10.1016/j.ejor.2010.10.001.

Zhang, R., Kaku, l., \& Xiao, Y. (2012). Model and heuristic algorithm of the joint replenishment problem with complete backordering and correlated demand. International Journal of Production Economics, 139(1), 33-41. http://dx.doi.org/10.1016/j.ijpe.2011.01.019.

Zhang, T., Huang, G. Q., Qu, T., \& Li, Z. (2013). Headquarter-centered common sourcing management through order coordination and consolidation. Computers \& Operations Research, 4O(8), 2011-2025. http://dx.doi.org/10.1016/j.cor.2013.02.021.

Zhou, W. Q., Chen, L., \& Ge, H. M. (2013). A multi-product multi-echelon inventory control model with joint replenishment strategy. Applied Mathematical Modelling, 374), 2039-2050. http://dx.doi.org/10.1016/j.apm.2012.04.054.

Received: Sept. 19, 2016 Accepted: Mar. 27, 2017 